Proc. of Eighth International Conference On Advances in Civil, Structural and Mechanical Engineering - ACSM 2018 Copyright @ Institute of Research Engineers and Doctors, USA. All rights reserved.

ISBN: 978-1-63248-154-2 doi: 10.15224/978-1-63248-154-2-30

\title{
CONTROL SYSTEM STRATEGIES FOR VIBRATION ASSISTED GRINDING MACHINE
}

\section{University of Medical Science \& Technology}

\author{
Heisum Ewad haythamawad122@hotmail.com. University of Medical Science and Technology, P.O. Box 12810, Khartoum, Sudan
}

\begin{abstract}
Grinding is usually the last finishing operation to be completed on the work piece and hence any deviations in quality such as geometrical errors and surface finish cannot be passed onto the next operation. Grinding is classified as a machining process that removes material from the work piece using similar principles to that of milling or turning. However, instead of having the one large cutting edge, there are numerous small cutting edges by way of grits on the grinding wheel surface, with all of them working together at extremely high speeds.

One of the main problems in grinding is the growing vibration (Chatter) between wheel and work piece during the process. Many studies and tests have been made in order to detect and avoid this dynamic phenomenon which affects a number of parameters including wheel wear and work piece quality. However, a possible method to prevent this type of chatter is to apply a periodic disengagement of the wheel from the work piece and periodic variation of the work speed.
\end{abstract}

This paper present a review of vibration assisted grinding. A development a controller for single axis vibration in grinding technology is reveal. A system calibration and experiment result including the forces, Power, grinding Coefficient, specific removal arte and specific energy software based control system is illustrated together with some results.

Keywords- Design of Controller, Experimental Result, Model Identification from the Data, Power Consumption.

\section{Introduction}

Several industrial processes are controlled using proportional integral- derivative (PID) controllers Goodwin et al, (2001). The acceptance of the PID controllers can be attributed to their good performance in a varied range in a simple, direct manner and familiarity Astrom et al, (2001) with which it is perceived amongst researchers and practitioners within the process control industries (Pillay and Govender, 2007).

In spite of its widespread use, one of its main short- comings is that there is no efficient tuning method for this type of controller (Astrom and Hagglund, 1995).

Some methods have been proposed for the tuning of PID controllers. Among the conventional PID tuning methods, the
Ziegler-Nichols method Ogata K, (1987) may be the most wellknown technique. For a wide range of practical processes, this tuning approach works quite well. However, sometimes it does not provide good tuning and tends to produce a big overshoot. Therefore, this method usually needs retuning before applied to control industrial processes. To enhance the capabilities of traditional PID parameter tuning techniques, several intelligent approaches have been suggested PID tuning, such as those using genetic algorithms (GA), (Mahnoy et al, 2000; Wang et al, 2003; Krishna and Goldberg, 1992) and the particle swarm optimization (PSO), (Gaing, (2004); Solihin et al, (2011). It has been asserted that more than half of the industrial controllers in use today utilize PID or modified PID control schemes (Ogata, 2005).

This wide spread acceptance of the controller is largely attributed to their simplicity and robust performance in wide range of operating conditions. One major problem faced in the deployment of PID controllers in the proper tuning of gain values (Visioli, 2001).

Over the years, various heuristic techniques were proposed for tuning the PID controller. Among the earliest methods is the classical Ziegler-Nichols tuning procedure, however, it is difficult to determine optimal or near optimal parameters with this because most industrial plants are often very complex having high order, time delays and nonlinearities (wok et al,1993 ; Krohling et al, 2001).

\section{Design of Controller}

The most important of this work is the real-time control of the amplitude oscillation. Most ultrasonic actuators are driven at resonance thus is mainly assumed that the amplitude is kept throughout the process. However, under cutting load the amplitude always fluctuates. In this work the oscillating stage was controlled in real-time to keep a constant amplitude in the cutting zone. To achieve this two controllers developed, one was based on the mathematical model given in equations (1-2) assuming that the stage is a single degree of freedom and the second based on the Black Box method.

$$
\begin{aligned}
& \left(m_{p z}+m_{r}\right) \frac{d y^{2}}{d t}+\left(C_{p z}+C_{r}\right) \frac{d y}{d t}+\left(K_{p z}+K_{r}\right) d t=F_{p z}(t)-F_{z}(t) \\
& \frac{d y^{2}}{d t}=\frac{F_{p z}(t)-F_{t}(t)-\left(C_{p z}+C_{r}(t) \frac{d y}{d t}-\left(K_{p z}+K_{r}\right) y\right.}{\left(m_{p z}+m_{m}\right)}
\end{aligned}
$$


The second controller was developed using actual experimental data as input to the black box method, therefore the equation of the real system was not needed. This approach proved to be more resilient as it dealt adequately with all disturbance i.e. cutting forces and oscillation.

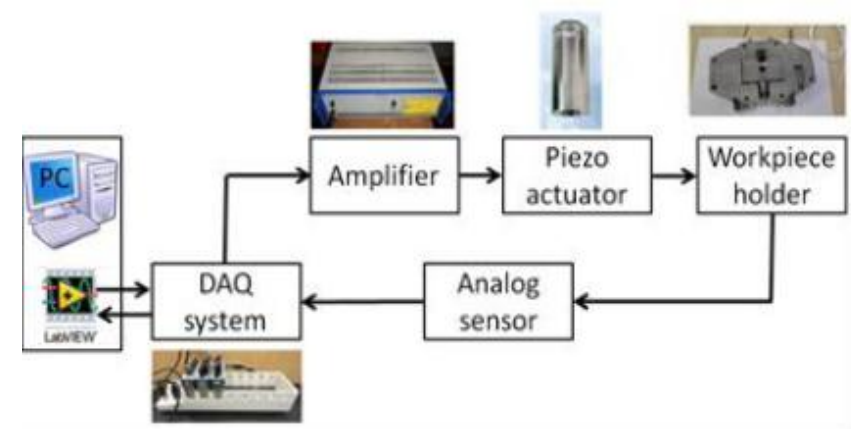

Figure 1: closed loop control set up for the experiment

The proportional-integral-derivative PID controller was designed to stabilise and control the amplitude of displacement of the vibrating jig. A proper model for the system has been built using a mathematical model. This model was used to find analytical solutions for the problem and to enable the prediction of the system behavior from a set of parameters and initial conditions.

To control the amplitude of the vibration of the oscillating jig, a basic PID controller was designed and simulated. The design involves control of the first mode of the vibrating system using a second order model. The controller output is sent to the power amplifier only when the displacement exceeds $130 \mu \mathrm{m}$.

The target of this work was to design a Lab VIEW based selftuning PID controller and to verify its performance in the actual vibration assisted grinding process. At the starting point an existing open loop system configuration was used to identify initial parameters. This was achieved in a series of test grinding, data collection and analysis. This allowed defining sets of parameters for the closed loop controller. In actual grinding tests, the controller reacted adequately to the persistent offset error value as a result of load disturbance or set point change. Practical result showed that such a controller may be adapted to control a variety of industrial processes.

The evaluation of the performance of the controller through the experiment was an essential part of the design. To substantiate the design and simulation results, the controller designed was incorporated into a full experimental set up based on initial and calibration results, the grinding trials were undertaken at frequency $100 \mathrm{~Hz}$, with a sinusoidal excitation signal of 4 volt peak to peak, which equated to $130 \mu \mathrm{m}$ oscillation amplitude.

\section{Model Identification from the Data}

A set of experimental data was acquired and as stated previously, the input and the output had been divided into two parts i.e. first subset contained 850 data points (1-850) and second subset contained 850 samples (851-1700). The first part of the input and output signals was used to obtain the vibration plant model and the second part of the input and output signals was used to validate the obtained model using the Matlab identification toolbox.

The following procedure was used. First, measurement data such as input voltage, sampling time and output acceleration was loaded in Matlab. Then the input signal (u) vector and output (y) vector were initialized in Matlab work space and the system identification toolbox was activated. The data (input and output data array) were imported and the starting point was set to zero and sampling interval to $0.001 \mathrm{sec}$. Figure 1 shows the time domain representation of observed data, both output acceleration and input voltage plotted with respect to the sampling time period.
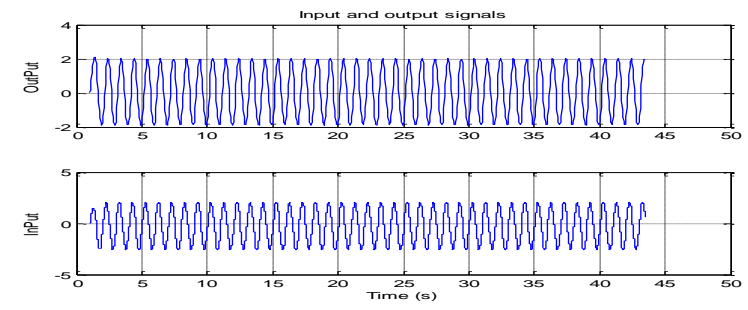

Figure 2: Time Domain Representation.

In Figure 3 show the technique used to measure the phase angle between two periodic signals. The technique works by tracking the location where the signals change from negative to positive. The exact zero crossing of the signals estimation is done by interpolating the negative and positive point.

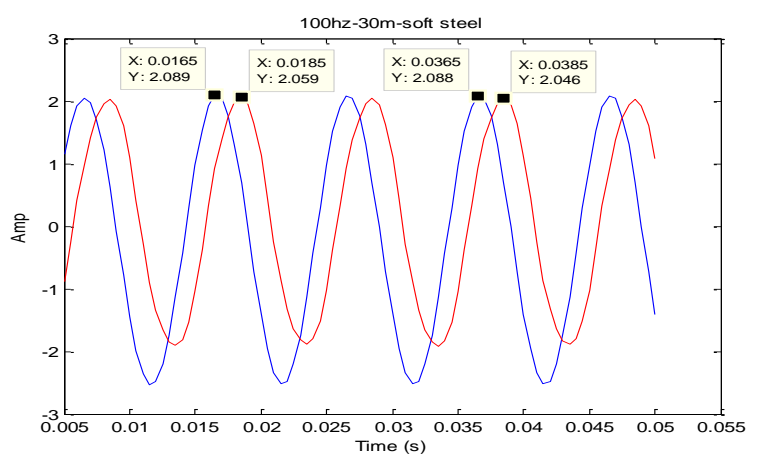

Figure 3: The Input and the Output Signals.

Using the ARX approach for identification, the result is compared with the time domain data following as illustrated in Figure 4. From this plot it is seen that the hypothesis limits are the red lines 
and it can be seen that none of the autocorrelations is significant the horizontal axis is the lag for the autocorrelation.
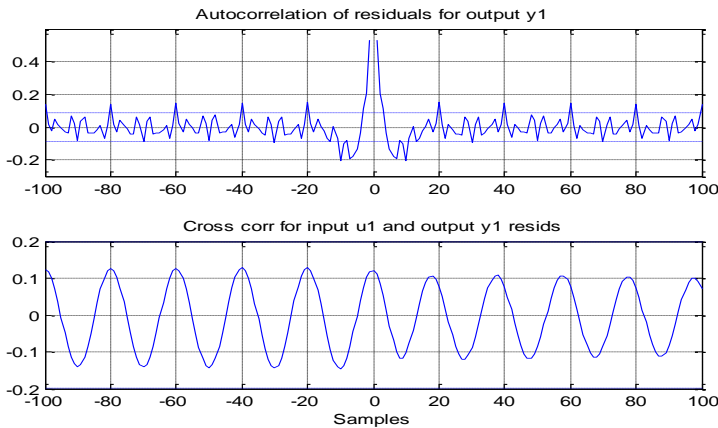

Figure 4: Model Parameter.

\section{Validation Result}

As the data were divided into two groups, the second lot of data was used to validate the correctness of the identified model. Using system identification toolbox, the model was validated and illustrated in Figure 5. For a given set of input data, the tool box computes the output of the identified model and by comparing the output with the measured output from the real system. It is found that the mode frequency obtained from the identified model is $91.09 \mathrm{~Hz}$ and it's close to the experimentally measured mode frequency $91.08 \mathrm{~Hz}$. This procedure helps avoiding over fitting as depicted in the flowing plot 5 .

(Heisum Ewad)

Faculty of Engineering / University of Medical Science and Technology (UMST)

SUDAN

E-mail: haythamawad122@hotmail.com

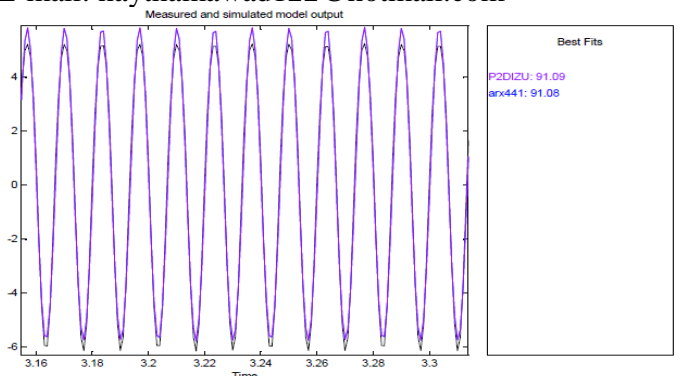

Figure 4: Validation

\section{Experimental Result}

The designed PID controller was aimed at reducing the error and eliminating the need for continuous operation attention. A set point is where the measurement is desired to be and the error is defined as the difference between the set point and the measurement. Thus (error) $=($ set point $)-($ measurement $)$.

The code is inside the M-script, the heart of strategic action and decision making of the controller. The controller outputs pass through gates that limit the outputs between 0 to 4 volts (i.e. $0-130$ $\mu \mathrm{m})$.

The outputs of the blocks are then given to the transfer function model. The controller output as well as output of the transfer function model are stored in the excel sheets during program runtime. The front panel displays the closed loop response with PI control and its control signal obtained through simulation is displayed in Figure 5. The designed values are $\mathrm{Kp}=800, \mathrm{Ki}=0.2$ and since Kd has very small action therefore it was opted for a PI controller. The simulation code shows in Appendix G, of the controller with the closed loop response signal obtained through simulation is shown in Figure 5.

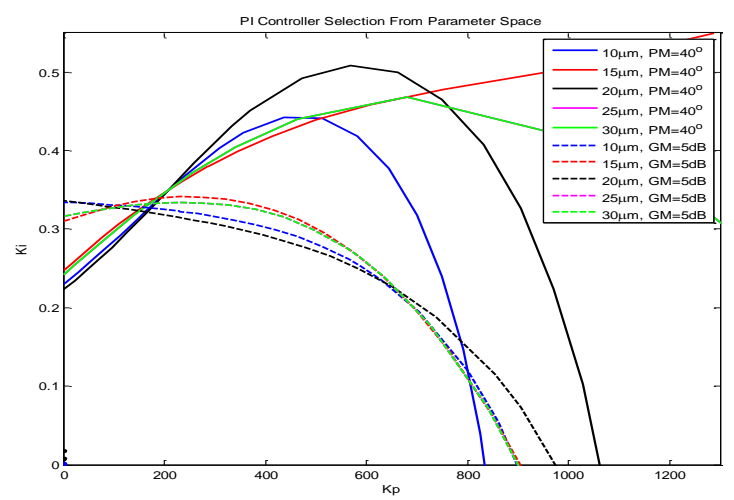

Figure 6: PI Controller Selection from Parameter Space

\section{Specific Grinding Energy}

Figure 6 shows the relationship between specific grinding energy versus specific removal Rate. As in the figures depicting the power, the specific energy expresses the energy spent to remove unit volume of material. The application of vibration to the grinding process reduced the energy requirement with reference to conventional grinding. However, it is observed that as the material removal rate increases, the specific energy for conventional grinding converges towards vibro-grinding. Grinding soft steel required more energy in both processes especially for small depth of cut. This is because soft material loaded the grinding wheel very fast, and this led to increased rubbing and frictional forces, which increase the power consumption. 

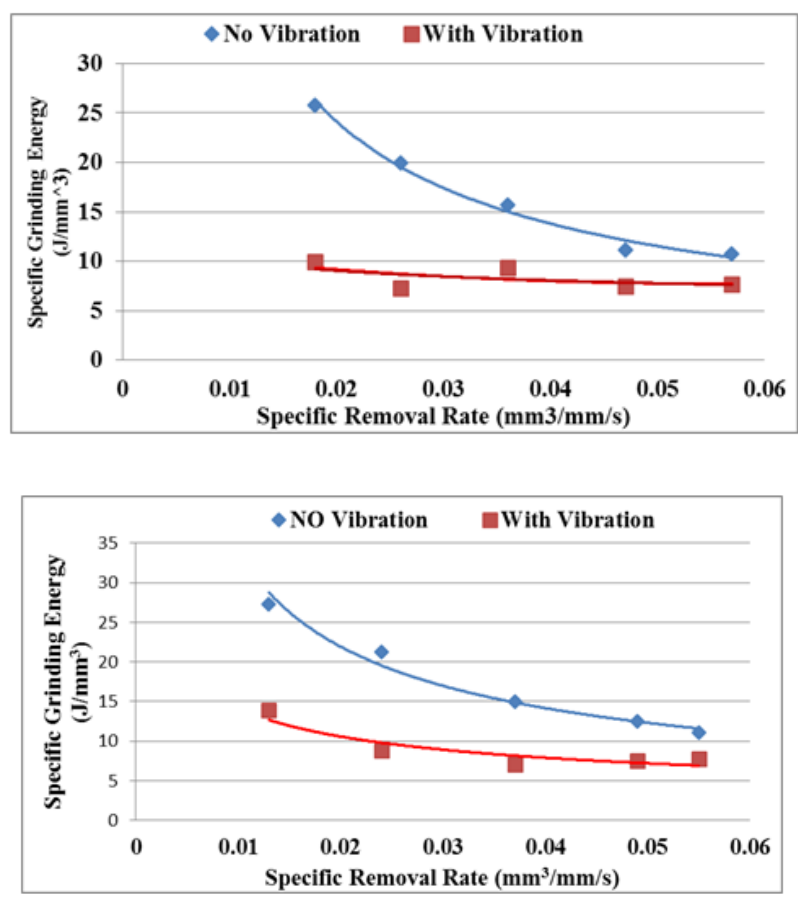

b)

Figure 6: Specific Grinding Energy: a) - Hard Steel; b) -

Soft Steel

\section{References}

[1] Malkin, Stephen (1989), Grinding Technology: Theory and Applications of Machining with Abrasives, Society of Manufacturing Engineers, Dearborn, and Michigan.

[2] Oberg, E., Jones, Franklin D., Horton, Holbrook L., and Ryffel, Henry H.(2000),

Machinery's Handbook, Industrial Press Inc., New

$$
\text { York, p.1190. }
$$

[3] Moriwaki, T., and Shamoto, E (1991). Ultraprecision Diamond Turning of stainless steel by applying ultrasonic vibration. Annals of the CIRP, Vol. 40, pp. 559-562.

[4] Matsumura, T. (2005) Glass machining with microend mill. Japan Society of Mechanical Engineers (JSME), Vol. 1, pp. 139-158.

[5] Marinescu I D, Rowe W B, Dmitrov B, Inasaki I, (2005); Tribology of abrasive machining processes.

[6] Gallemaers J P, Yegenoglu K, Vatovez C, (1986); Optimizing Grinding Efficiency with Large Diameter CBN Wheels; Int. Grind. Conf. Philadelphia.

[7] Brehl, D (2008). Review of vibration assisted machining. Precision Engineering, Vol. 32, pp. 153-173.

[8] Cerniway (2005), M. Elliptical Diamond Milling: Kinematics, Force and Tool. Msc Dissertation Graduate Faculty, North Carolina State University,

[9] Bonifacio, M. And Diniz, E (1994). Correlating tool wear, tool life, surface roughness and tool vibration in finish turning with coated carbide tools. Wear, Vol. 173, PP. 173-144.

[10] Chern and L., and Change, (2006) C.Using Towdimensional cutting for micro- milling. International Journal of Tools \& Manufacture, Vol. 46, pp.659-666.
[11] Zhou M, Eow Y, Ngoi B, Lim E, (2003) "Vibration-assisted precision machining of steel with PCD tools". Mater Manuf Process; 18:82534.

[12] T siakoumis V. I, (2011) an investigation into Vibration assisted Machining - Application to surface grinding Processes $\mathrm{PhD}$ thesis LJMU.

[13] Chen, X., Rowe, W.B., Mills, B., (1996) 'Analysis and simulation of the Grinding Process' International Journal of Machine Tool \& manufacturing. 36, issue 8, pp871-906.

About Author :

\section{Heisum Ewad was born in MADANI/}

Sudan, on December 31, 1974. I received B.sc degree in Electrical and Electronics from Liverpool john moores university (UK), in 2008. M.sc degree in Manufacturing Engineering from Liverpool john moors university (UK), 2009. And finally $\mathrm{PhD}$ in Control Engineering from Liverpool john moors university (UK) 2015, Currently Dean Faculty of Engineering at University of Medical Sciences and Technology / Sudan 